wards the bottom of the vessel, to which they will fall by degrees, giving a reddish colour to the lower strata of the liquid. At the same time the spots on the texture will become discoloured, and covered by only a thin layer of a greyish-coloured substance. 'This is fibrin, with a proportion of the red particles remaining undissolved; the reddish flaments descending to the bottom are, on the contrary, the globules of colouring matter. Now carefully remove the texture, with its adherent fibrin, and on stirring the liquid with a glass rod it will acquire a rosy tinge. Heated gradually to near the boiling point, it becomes turbid, and either deposits flocculeut albumen, or assumes a pearly appearance. If flocculent matter be thrown down, it is of a greenish-grey, without a tinge of red or rose colour, and the supernatant fluid, if not destitute of colour, is of a light greenish-yellow. If the liquid be treated with pure potass it assumes a colour which is greenish, or rosy, according as viewed by reflected or refracted light. No colouring matter of any other animal product so treated will give rise to similar phenomena. The filaments of fibrin left on the texture are soft, rather elastic, and soluble in a solution of caustic potass, and the resulting solution, treated with a little hydrochloric acid and free chlorine, gives rise to a flocculent deposit of animal matter.

The French physicians have latterly been directing their efforts to find a mode of distinguishing, if possible, the blood of different kinds of auimals. M. Barruel (Annales d'Hygiène, tom. i., 267,) has gone far beyond his competitors in this march. His process is to place the blood to be experimented on in a glass, and to add to it about one-third or half its volume of sulphuric acid. On agitating the mixture with a glass rod, a volatile odoriferous principle is given off, peculiarly characteristic, he says, of the blood of different kinds of animals, and the differences in which are to be detected by the sense of smell. M. Barruel asserts, that by this test he can even distinguish the blood of the male from that of the female, but as few persons pretend to such acuteness as that, the correctness of his researches has hitherto met with few advocates. The most that we have been able to ascertain positively upon this subject is, that the coloured globules in the blood of man and mammiferous animals are circular, while those in oviparous animals are elongated, with an elevation in their centre corresponding to the place of the nucleus. Among the mammifera a remarkable exception exists, en the authority of MM. Milne Edwards and Geoffroy St. Hilaire, in the camel genus, the red globules in the blood of which are elongated as in the oripara; but, in the present state of animal chemistry, we have no means of distinguishing between the blood of any other kinds of mammiferous animals.

\section{CASE OF STRANGULATED HERNIA, WITH}

HYD R OCLE OF THE SAC, AND OPERATION.

WITH REMARKS ON THE NATIRE OF

\section{HERNIAL SACS, AND THEIR TREATMENT.}

By John Gay, Esq., Surgeon to the Royal Free Hospital, the Provident Clerks' Assurance Society, \&c.

A Litrue type-compositor, atal. 17, named William Watkins Wynn, applied at the Royal Free Hospital, on the 6th of September, with a swelling along the course of the spermatic cord, which had the usual appearances of oblique serotal hernia. Mr. Waugh (who was in atteudance for me), with Mr. Hill, the house-surgeon, taking this view of the case, instantly attempted its reduction by taxis, but could not succeed in removing the tumour. The lad was then placed in a warm-bath, faintness soon ensued, and by means of a little manipulation at this crisis, the swelling was made to disappear as though the contents of a hernial sac had been returned into the abdominal cavity. In a few hours the boy recovered and left the instilution.

Three days afterwards he made his reappearance amongst my out-patients, and stated that on the day following that on which he before applied, after some exertion, the rupture again took place, and had remained, notwithstanding his endeavours, in imitation of those which had before been successful, to return it. The swelling had now become painful, especially that part of it within the inguinal canal, and the bowels had not been relieved since its appearance. His countenance was pale and betrayed a little anxiety, so that I lost no time in examining the cause of complaint, and discovered on the left side a swelling which ran along the course of the inguinal canal and cord to the globus major epididymis, the testis being situated beneath and the cord behind it. It was apparently uniform in its consistence, tense, and somewhat constricted at the situation of the outer ring. 'The act of coughing gave a considerable impulse to every part, but the succussion was most strongly felt at two points, viz., at the point of constriction and at its fundus in the scrotum.

These symptoms, together with the account which I had of what transpired on his previous appearance at the hospital, led me at once to suspect that it was a case of hernia, and to attempt its reduction by the usnal means, without any delay. Four hours had now elapsed since his ad. mission, and our endeavours to procure relief were found to be unsuccessful. The 
pain in the tumour, and upon pressure in the lower part of the abdomen, had increased; the boy's countenance indicated more anxiety, and nausea had supervened; circumstances which induced me at once to resort to an operation. It should here be stated that the peculiarity about the general aspect of the tumour, which resulted principally from the hour-glass contraction, gave rise to some doubts in the minds of Messrs. Coulson, Taunton, and other friends present, as to its wholly consisting of intestine; and under the impression that it was a complex case, the complication, in all probability, being hernia with hydrocele of the cord,

the operation was commenced.

The patient was laid upon the table in the usual manner, and an incision made through the integuments from about the situation of the external abdominal ring to nearly the lower end of the tumour. Proceeding by cautious dissection, the sac was reached and opened by a small sidelong incision; with the aid of a director it was then slit up; about two ounces of fiud escaped, and at this moment a knuckle of intestine was observed just protruding from the external ring, in a condition which betokened its having been subjected to constriction for some time. It was readily returned through the inguinal canal into the abdomen upon the tip of the fingel, the lad being at this moment faint, and in the act of vomiting. The relaxation of the stricture which permitted the intestine to return without its division, depended probably, in part, upon the relief to the tense condition of the sac consequent upon the discharge of its fluid contents, the constriction having, upon the same hypothesis, been aggravated by that tension. The bleeding was of no consequence, a pledget of lint was cautiously laid in the sac, the edges of the wound were brought together by sutures and adhesive plaster, reserving a sufficient space for the removal of the lint; cold-water dressing completed the topical applications, and the lad was then removed into bed.

\section{On the day following,}

as an important amount of inflammation was observed to have been set up in the sac and along the parietes of the inguinal canal, and pressure in the abdomen gave a little uneasiness, I had the lint removed. Suppuration, with slight febrile action, followed, but not more than the process of healing seemed to require, and ultimately complete obliteration of the sac. Two abcesses of the scrotum formed during the healing, one just beneath the root of the penis, the other further back towards the pudendum; they were opened, discharged their contents, and closed up. The boy was discharged on the 19th of October.

After the operation a difference of opinion was found to exist as to the nature of the sac and its relation to the protruded intestine. My impression on opening it was that it was lined with peritoneum; that, in fact, it was a cul-de-sac continuous with, and opening itself into, the peritoneal cavity of the abdomen, and that the knuckle of intestine had descended so far into it as the fluid contents of the sac would permit, and became constricted at the external ring, directly by its pillars, and indirectly, as $I$ have before stated, by the extreme distention of the portion of the sac below it. Another suggestion was that it was a case of hernia with common hydrocele of the cord; and, in accordance with this, which appeared to be the predominant opinion, I adopted, as the after treatment, stimulation of the sac, with a view to its ulterior obliteration. The almost immediate consequences of that procedure (inflammation of the parietes of the sac and inguinal canal) obliged me to withdraw the lint at the end of twenty-four hours, and I then endeavoured to make the real nature of the case more clear by cautiously traversing the interior of the cyst and its outlets by means of a curved probe. On introducing that in. strument for this purpose, I soon found that it passed readily, and without any obstacle, into the inguinal canal, and through it towards the abdominal cavity, so far as its length and the swollen condition of the parts would permit; and therefrom I felt convinced that the sac was peritoneal, and directly communicated with the abdomen.

The question as to the production of the sac next presented itself to my mind, and I can have no hesitation in believing it to have been congenital, and to have resulted from a non-occlusion of the greatest portion of the channel which in the foetus existed between the abdominal cavity and the tunica vaginalis testis. And $I$ do not see why this arrest in the obliterating process with regard to that channel should not be called to our aid in elucidation of a circumstance connected with the production of most heruial saes, which has not as yet, as far as $I$ am aware, received a satisfactory explanation. I refer to

The adhesion of the sac to the parts among st which it is found

Mir. Lawrence states that ${ }^{6}$ adhesion takes place so quickly that we find the sac universally connected to the contiguous parts, even in a rupture of a few days' standing; and these connections become afterwards so strong and general that we might suppose the hernial sac to have been originally formed in its unnatural situation." This is the sum and substance of what writers on hernia appear to know of the hernial sacs; but $I$ cannot admit the position, because it is unsupported by the symptoms and other circumstances which usually attend upon the descent of a hernia. In some cases, it must be admitted, the intestinal protrusion is gradual; the patient complains of some un. 
easiness about the groin which, probably, on the opposite side in five, and completely together with some dyspeptic complaint, has annoyed him for some time, and the surgeon, on searching for the cause, discovers the abdominal parietes in that situation apparently thin or "weak" (as it is commonly expressed), and that an unnatural impulse is communicated to the hand in coughing. If neglected, a swelling makes its appearance ; the intestine is forced gradually to insinuate itself through the inguinal canal into the scrotum; the cellular, and other tissues in its course, give way before it, with the occurrence of well-marked uneasiness, and thus form a receptacle, occasionally of an enormous size, for the stretched peritoneal sac and its contents. This description of case is, however, rare, in comparison with another in which the descent occurs early in life and suddenly, and in which the hernial mass rarely becomes so bulky. In the "Traite Pratique des Hernies, \&c." par P. L. Verdier, the author gives a table of the comparative frequency of hernia at different ages, from which it would appear that out of 1226 cases which were known to him, 973 occurred under the age of ten years; 152 between the ages of ten and twenty; 57 between twenty and thirty; 25 between thirty and forty; 11 between forty and fifty ; and 8 between fifty and seventy; showing very plainly that by far the greater number of hernial descents occur to the young. Now, there is wanting in the history of these cases, I mean of those which take place suddenly and in early life, an account of the disturb. ance and inflammation which would most assuredly accompany the bursting of a hernial mass into the scrotum, and attend the perfect adhesion of the sac to the surrounding textures, supposing the sac to be formed by dilatation, and protruded at the time the hernia is observed. I firmly believe the contrary to be the fact; and lhat, as in the case introductory to these remarks, the sac is congenital in by far the large majority of cases, and results either from an absolute want of, or arrest in, the processes of obliteration, which usually occlude the channel of communication between the tunica vaginalis testis and abdomen in foetal life. In this, as in many cases, the obliteration had commenced on the scrotal side of the canal, and the fact of the testis being in this manner separated from the hernial sac would distinguish this from that form of hernia usually termed "congenital," in which the intestine and testis are in juxta-position.

The obliteration of the channel to which I have been alluding does not unfrequently happen. In the course of my dissections I have found it patent in three instances at the ages of two, three, and eight. Camper dissected seventeen newly-born children for the purpose of ascertaining this point, and found the canal open on both sides in eleven, obliterated entirely on one, and but partially closed up on both sides in one only. Wrisberg made similar observations; but it is only just to state that in the attempt to make such discoveries some eminent anato mists, amongst whom I may reckon Mr. Lawrence, have failed.

These considerations have satisfied me of, at all events, the great probability that in the majority of hernial cases, especially in those which occur in the season of youth, when activity, even to violence, is most freely and frequently indulged in, the formation of the sac is antecedent to the period at which the hernia manifests itself; that, in fact, the sac is congenital, and results from an arrest in the processes which usually com. plete the obliteration of the canal, which, upon the descent of the testis, forms a communication between its serous tunic and the cavity of the abdomen.

From what has already been adduced, hernia appears, in such cases, to be attributable mainly to a defect in the processes of adhesive inflammation which naturally take place at a certain period in the tissues of the infantile spermatic cord; and I see no reason why, when such a defect has been detected by a hernial protrusion, and as a supplement to an operation, it may not be safely remedied by means adapted to procure the action in default; in other words, by means adapted to excite inflammation in, and obliteration of, the sac. Surely, in thus imitating the processes of Nature, and supplying her defects, surgery cannot be charged either with rashness or caprice. I am aware that my proposal is not new, - that various devices have been resorted to in order to effect the same important end, some dangerous and cruel, others less severe and comparatively imocent, but all without the rationale for their adoption which I believe these considerations are adapted to supply; and, therefore, for the most part, these operations have been abandoned as useless and even eminently hazardous.

Oue of the most serious obstacles to the steady advancement of medical and surgical art is, probably, the custom which has too much obtained of yielding an undue, nay, a blind credence to the axioms of ancient pathology. Hence, an incalculable amount of maliguity is fancifully ascribed to some diseases, so that the bare mention of their names in proposing a surgical operation, is sufficient in the minds of some practitioners of modern times to forbid its consideration, much more its sanction. Foremost in the category of diseases to which I have just referred I would place "peritonitis," and believe that the false uotions of danger attributed to it, in total disregard of the condition under which it may exist and by which its results must invariably be modified, have proved a serious hindrance to the progress of surgery. In an wnhealthy state of 
the system the raising of a blister might, perchance, be followed by fatal consequences; and spontaneous peritonitis, as it generally occurs in individuals unfavourably predisposed, is ever replete with danger; but it does not follow, in my opinion, that the same inflammation procured in a system otherwise in a state of health, and especially in a comparatively remote channel, which has no functional intentions to fulfil, and which Nature has in vain attempted by the same process to occlude, is to be regarded with equal apprehension. I have yet to learn that which neither my own experience nor the retrospect of the fatal cases of incarcerated hernia on record have taught me, viz, that the mortality after these operations, as well as after others in which the peritoneum has been injured, has resulted from pure traumatic peritonitis; and, on the contrary fearlessly hazard the opinion that this membrane, in a healthy individual, may be wounded with comparative impunity.

In the case now related the adhesive infammation was set up by means of

\section{A piece of lint introduced into the satc,}

and allowed to remain for twenty-four hours, a period equal to the production of an amount of inflammatory action sufficient to ensure its obliteration. 'This is the plan which I now beg to propose for the consideration of the profession. Of course it would not be suitable for old and large hervial sacs; the cases must be selected by the surgeon; and, in my opinion, that would be the best calculated for such treatment in which the sac is small and the intestinal descent has been recent. A single case is, I am aware, not sufficient, however favourable, to warrant the adoption of this treatment as a rule; my object in bringing it before the profession is to obtain a just estimate of its reasonableness and practicability.

P.S. A similar case, but occurring in earlier life (at the age of fourteen months), is mentioned by Mr. Lawrence, in his work on hernia, page 59, second edition; proving, as Mr. L. says, an exception to the general rule laid down by $\mathrm{Mr}$. Pott, "that all those ruptures which appear in the scrotum of young children are congenital." 'The operation for incarcerated hernia was successfully performed, but the hernia appeared again afterwards.

Finsbury Pavement, Nov, 12th.

"Essence of camphor is made by dissolving camphor in solution of muriate of ammonia." -Dr. Traill.

"A very good cream is formed by mixing up magnesia, calcined, with afterings of milk."-Dr. Traill.

\section{SULPHURIC ACID A PREVENTIVE OF LEAD COLIC.}

\section{To the Editor of The LANCET.}

Sir,-The permission to make use of your widely-circulated Journal to publish the means which have been found perfectly successful in preventing that most distressing malady, the lead colic, to which the workmen employed in the manufacture of white lead are so liable, would oblige, Sir, your's very rospectfully,

\section{E. W. Benson,}

Managing Director of the Works. British White-Lead Works, Birmingham, Dec. 10, 1842.

Soon after the establishment of the British White-Lead Works, and for some succeeding years, the lead colic prevailed amongst the workmen to a very distressing extent. The usual precautions were adopted of providing the workmen with gloves, and of enforcing strict attention to cleanliness on their part, ample means for this purpose being at the same time supplied, the men also being caused to change their working dresses on leaving their employment. Effective means, moreover, were adopted for carrying off the dust which arises in some of the operations, thus preventing as much as possible the inhalation of particles of white lead suspended in the air. The work-people had also a regular medical attendant provided by the proprietors of the works.

Notwithstanding the precautions thus adopted, the observance of which was carefully enforced, some of the work-people were constantly suffering from illness, and in the hot season the number of cases of colic much increased.

The copious use of treacle-beer has been considered at many white-lead works to be serviceable, to some extent, as a preventive of this malady, and the beverage was supplied ad libitum in our establishment.

I net with a statement some time since, that "sulphuric lemonade" had been successfully used at a white-lead manufactory in France as a preventive of the injurious effects of white lear, and it occurred to me that by adding sulphuric acid to the treaclebeer then used by our people, its supposed efricacy might be tested. This idea was carried into effect in the summer of 1841, and the results have proved most gratifying, as, although during several weeks after the ad. dition of the sulphuric acid to the treacle beverage, little advantage seemed to be derived, yet the cases of lead colic became gradually less frequent, and since October of that year, or during a period of fifteen months, not a single case of lead colic has occurred amongst the people.

As no other change has taken place in the circumstances under which these men are 